Portland State University

PDXScholar

6-6-1995

\title{
The Effect of Psychological Gender and Self- monitoring on Leader Emergence and Leader Behavior
}

Janet Day Goldsmith

Portland State University

Follow this and additional works at: https://pdxscholar.library.pdx.edu/open_access_etds

Part of the Psychology Commons

Let us know how access to this document benefits you.

\section{Recommended Citation}

Goldsmith, Janet Day, "The Effect of Psychological Gender and Self-monitoring on Leader Emergence and Leader Behavior" (1995). Dissertations and Theses. Paper 4974.

https://doi.org/10.15760/etd.6850

This Thesis is brought to you for free and open access. It has been accepted for inclusion in Dissertations and Theses by an authorized administrator of PDXScholar. Please contact us if we can make this document more accessible: pdxscholar@pdx.edu. 
THE EFFECT OF PSYCHOLOGICAL GENDER

AND SELF-MONITORING

ON

LEADER EMERGENCE AND LEADER BEHAVIOR

by

JANET DAY GOLDSMITH

A thesis submitted in partial satisfaction

of the requirements for the degree of

\author{
MASTER OF SCIENCE \\ in \\ PSYCHOLOGY
}

Portland State University

1995 


\section{PROBLEM STATEMENT}

American society tends to evaluate managers' and leaders' success in terms of masculine sex-typed behaviors, even in the face of disconfirming evidence that these behaviors are unrelated to effectiveness and sometimes counter-productive. Men in general are described as more similar to successful managers than are women (Heilman, Block, Martell \& Simon, 1989). Male middle managers still adhere to male managerial stereotypes, whereas many women now view a managerial position as free from sex type (Brenner, Tomkiewicz \& Schein, 1989). Furthermore, research on leadership emergence has found that men emerge as leaders more often than women even though their subordinates often report no difference in leader behavior (Eagly, \& Karau, 1991). Taken as a whole, this research suggests possible foundations of the "glass ceiling;" the invisible barrier that prohibits women from advancing beyond certain points in organizations.

Recent research has shown consistently that there are no sex differences in the overall effectiveness of managers and leaders (Powell, 1988, 1989; Freedman \& Phillips, 1988; Eagly \& Johnson, 1990). The results of these studies indicate a pressing problem; women are still being limited in their career options by stereotypical biases, or sexism, because many people still view a leader as being masculine or male.

These theoretical and practical issues lead to this investigation into the unbiased nature of leadership. What is a leader? Who emerges as a leader? Why do some people emerge as leaders and most importantly, aside from stereotypes, what makes an effective leader? 
Finally, what factors other than sex, correlate with or modify leadership behavior?

An effective leader is one who can adapt and respond constructively to both task and relational situations. Organizational research has shown that the presence of both 'consideration', or employee- oriented behavior and 'structuring,' or production- oriented behavior is necessary to be an effective leader. Considerate leader behavior is correlated with the feminine sex-type and structuring leader behavior is correlated with the masculine sex-type (Cann \& Siegfried, 1990). Differences in leadership and management style have been found, however, these differences are associated more directly with psychological gender than biological sex (Cann \& Siegfried, 1990). Psychological gender refers to a person's sex-role orientation: including "masculine," or a person with stereotypically masculine behaviors; "feminine," or a person with stereotypically feminine behaviors; and "androgynous," a person who is high on both masculine and feminine behaviors.

\section{BIOLOGICAL SEX \& PSYCHOLOGICAL GENDER}

Children grow up believing they have limitations imposed by their sex. Adults assess others' occupational ability based on biological differences. Our society has correlated biological sex with a number of unrelated behaviors (Bem, 1984). Women are seen as more nurturing, dependent, sensitive, and better listeners; while men are seen as more assertive, independent, analytical and less sensitive. These stereotypes 


\section{THESIS APPROVAL}

The abstract and thesis of Janet Day Goldsmith for the Master of Science in Psychology were presented June 6, 1995, and accepted by the thesis committee and the department.

COMMITTEE APPROVALS:

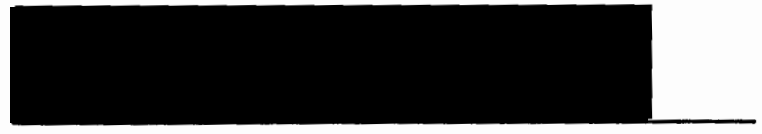

Dean Frost, Chair

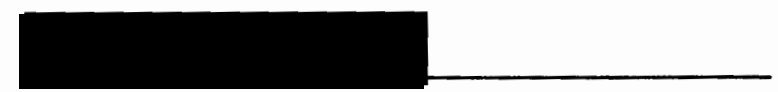

Laurie Skokan

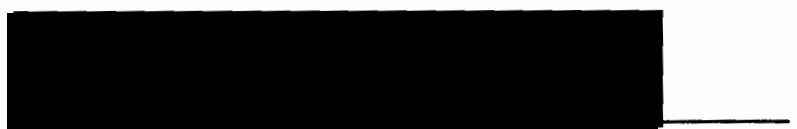

Robert Eder

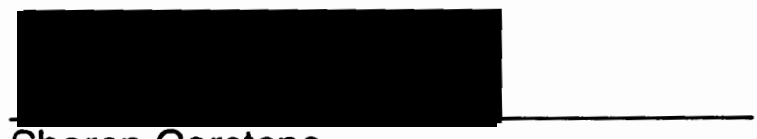

Sharon Carstens

Representative of the

Office of Graduate Studies

DEPARTMENTAL APPROVAL:

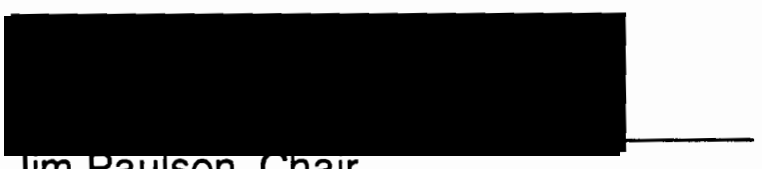

Jim Paulson, Chair

Department of Psychology

ACCEPTED FOR PORTLAND STATE UNIVERSITY BY THE LIBRARY

by

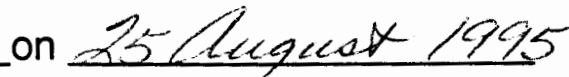




\section{ABSTRACT}

An abstract of the thesis of Janet Day Goldsmith for the Master of Science in Psychology presented June 6, 1995.

Title: The effect of psychological gender and self-monitoring on leader emergence and leader behavior.

Leadership has traditionally been associated with masculine sextype characteristics. Feminine characteristics have been undervalued or even viewed as a liability. One result of this is a diminished number of women in leadership roles.

Masculine sex-typed characteristics, such as self-reliance, assertiveness and analysis are associated with task-oriented behavior or a production emphasis. However, organizational research has shown that the most effective leaders engage in not only task-oriented behavior but also relationship-oriented behavior. Consideration for employees, or relationship-oriented behavior, has been associated with feminine sextype characteristics (e.g., compassionate, loyal, and understanding). Thus research indicates that, contrary to popular belief, an individual who displays both masculine sex-typed behaviors (e.g., initiating structure) and feminine sex-typed behaviors (e.g., consideration), would be the most effective leader. This person's psychological gender, as identified by the Bem Sex Role inventory, would be androgynous. In addition, it has been hypothesized that those individuals who are high self-monitors, or who are the most adaptive to a group's environmental needs would serve as the best leader. This study, then, examines how the presence of androgyny 
and high self-monitoring affect the leader emergence and leader behavior in small, long-term, work groups.

The results of this study provide few new contributions to the field. In almost all cases, hypotheses were not supported by significant differences in groups of subjects based on psychological gender and selfmonitoring. However, differences in outcome measure means, although not significant, were often in the expected direction. Furthermore, exploratory analyses suggest that if the sample size had been larger, many of the hypothesized relationships would have been supported by the results. As suggested above, the sample size, which was smaller than expected, was deemed insufficient to draw out significant relationships. After splitting the groups twice due to psychological gender and selfmonitoring, the small cell sizes negatively affected the power of between subjects comparisons.

Suggestions for further research include a larger sample size, the inclusion of variables such as power bases and flexibility, and, in defining leadership for the subjects, a stronger emphasis on process activity. 
serve to limit the range of behaviors of all people. Many people talk about sex differences as if having a vagina or a penis automatically produces nurturing in women and assertiveness in men. There are sex differences; women and men are anatomically different, however, the "sex differences" that most of society discusses are almost certainly accounted for by something other than biology (Bem, 1984). For example, women and men are socialized differently. This usually results in general differences in the way men and women interact. Depending on the information received and the way all information is processed, children develop quite differently. Thus, although there are very few behavioral sex differences, there are more "gender differences" (Bem, 1984). When one discusses "sex differences," one is talking about those differences between people of differing anatomy, men and women. This is quite different from talking about "gender differences," those differences between people of varying psychological gender, or sex-type. In discussing gender differences, one does not differentiate between groups by biological sex, rather by the gender identity of the individual. This gender identity is something that develops in the individual through the interaction of the self and the environment; although it is influenced by biological anatomy, gender is not determined by anatomy. The gender identity is part of an individual's self schema, which develops over time (Signorella, 1987). The self schema is the organization of associations, categorizations and concepts that a person sees as her or himself. The self schema serves to orient attitudes, beliefs and behaviors (Fiske \& Taylor, 1991). When a person views the world as 
divided by female and male distinctions, he or she has a gender schema (Bem, 1984). In forming sex distinctions, or in holding gender schemas, people form and reinforce sexist stereotypes which function to limit people's options. Ideally, people of all sexes or races can have the freedom of choice about their behavior independent of arbitrary biological factors. People can choose traditional, or stereotypic lifestyles or they can choose alternative lifestyles. The point is, the individuals choose their lifestyle; it is not defined by one's biological sex.

\section{BIOLOGICAL SEX AND LEADERSHIP}

\section{Biological Sex and Leadership Emergence}

The question of whether men do in fact emerge as leaders to a greater extent than women is a vital one. This question verifies or disconfirms the rationale for a "glass ceiling." Furthermore, answers to this question might offer some explanation for the tendency for most leadership roles to be occupied by men more often than women.

Eagly and Karau (1991) conducted a meta-analysis on biological sex and leadership emergence using 75 studies. The authors reviewed research on the emergence of male and female leaders in initially leaderless groups in both laboratory and field studies. Based on the gender role view of group behavior, men are expected to possess high levels of agentic or instrumental qualities, while women are expected to possess high levels of communal or expressive attributes. Thus, consistent with the these stereotypes, the authors predicted that the meta-analysis should reveal that men emerge as leaders more often than 
women. This tendency was predicted to be stronger when leadership was defined in terms of a task contribution. However, women were predicted to emerge as leaders to a greater extent than men when leadership was defined strictly in terms of social contribution.

Furthermore, the gender role perspective suggests that the tendency for men to lead should diminish over time because as the interaction progresses group members obtain detailed information about attributes other than gender. So, over time, group members become familiar with actual member competencies and elect leaders based on this information instead of inaccurate stereotypes. Thus, the authors postulate that, if task-relevant competence is distributed relatively independently of biological sex, the tendency for men to be leaders should diminish the longer that group members interact and the longer they delay their choice of leader.

As expected, men emerged more frequently than women on the task and unspecified leadership measures, whereas women emerged more frequently than men on the social leadership measures. Thus, sex differences in emergent leadership depend on the type of leadership measured. The tendency to choose men may reflect a tendency to define leadership in terms of task - oriented contributions. Helping the group work through its interpersonal problems and maintain morale may be less likely to result in selection as the group's leader (Eagly \& Karau, 1991).

Results also support the expectation that the longer the group interaction, the weaker the tendency for men to emerge as leaders. 
Again, as predicted, the tendency for men to become leaders lessened when tasks required relatively complex social interaction. Finally, there was a stronger tendency for men to emerge in laboratory groups than in natural groups.

This meta-analysis offers some possible answers to the question about sex differences in leadership emergence. First, group members often define leadership only in terms of task-oriented behaviors, excluding relationship-oriented behaviors. Second, group members, faced with limited time and information, elect leaders based on stereotypes for men and women. Since men are expected to possess agentic or task- oriented attributes, men are elected leaders more often than women in simple, short term groups. This tendency decreases when the groups exist for longer periods and have more complex social interaction. In these situations, members can judge a person's leadership abilities independent of sex stereotypes. Finally, more complex and long term social interactions require a leader that can manage both task and relationship oriented problems.

\section{Biological Sex and Leadership Style}

Founded on interview and personal experience research, popular management literature has for some time been publishing reports of the presence of sex differences in leadership style. In contradiction to this, social scientists have consistently found no sex differences in leadership style of leaders within organizations. Based on the contradictory evidence of social scientists and popular managerial literature, Eagly 
and Johnson (1990) conducted a meta-analysis of biological sex and leadership style research. Although consistent sex differences have been found in other areas of social psychology, Eagly and Johnson (1990) believe that both the structure of the organization, and the presence of those who have chosen to become a professional leader, forms an organizational context wherein those of different sexes are equivalent leaders.

The authors reviewed 329 articles about leadership style and sex differences with the intent to compare sex differences of leaders in organizational studies versus leaders in non-organizational studies. Non-organizational studies included laboratory experiments and assessment studies, which were defined as research that assessed the leadership styles of people not selected for occupancy of leadership roles. They examined two aspects of the leaders' work; task accomplishment, or organizing activities to perform assigned tasks; and maintenance of interpersonal relationships, or tending to the morale and welfare of the people in the setting. Another leadership style distinction studied was the dimension of democratic, or autocratic leadership (i.e., participative versus directive). Both sets of these constructs are related to the feminine or communal orientation and the masculine or agentic orientation. Task and autocratic leadership style was related to the masculine orientation and interpersonal and democratic leadership style was related to the feminine orientation.

As predicted, Eagly and Johnson (1990) found that men and women leaders do not differ in the use of either interpersonally-oriented 
style or task- oriented style in organizational studies (effect size $=-.00$ ). These results were compared with results from lab experiments and assessment studies which investigated people who were not selected for occupancy of leadership roles. In these non-organizational studies, the authors found leadership style was more sex stereotypic (effect sizes = .12 and .22 , respectively). In all three types of studies the authors found that women tended to adopt a more democratic or participative style and a less autocratic or directive style than did men (effect size $=.29$ ). Comparisons of effect means across all studies equaled .02 , with most of the effect sizes ranging from .00 to .10 .

This meta-analysis of the current research on sex differences in leadership style reveals an interesting moderator. The comparison between organizational and non-organizational studies reveals a difference in the individuals who choose to become professional leaders. Within the organizational context, there is little difference in leadership between men and women. This is contrasted to the sex differences found in studies of leadership among people who have not chosen to be leaders. These meta-analytic results seem to point to the presence of a confounding and more direct variable; that of psychological gender. Those individuals who are masculine or androgynous sex-typed would be more likely to choose to become leaders in businesses than individuals who are feminine sex-typed (i.e., those who would be more likely to choose to become teachers, nurses, pastors, etc.). From this perspective, it would be natural to find equivalent leadership styles among men and women in organizations because one would be actually 
be comparing people of similar psychological gender. Furthermore, because there is a correlation between sex-type and sex, one would expect more stereotypic sex differences outside of organizations where there isn't a selection bias for certain psychological genders. Since the reviewed research shows that there are few significant and consistent biological sex differences in leadership style, it seems the more meaningful variable to examine with leadership would be psychological gender.

\section{PSYCHOLOGICAL GENDER AND LEADERSHIP}

\section{Conformance to Gender-Role Beliefs}

Bem has developed a tool to measure a person's sex-role or gender identity. The Bem Sex-role Inventory (BSRI) is a paper-andpencil self-report instrument that asks the respondent to indicate on a 7 point scale how well each of 60 attributes describes him or her (Bem, 1984). Twenty of the attributes reflect the culture's definition of masculinity, 20 reflect the culture's definition of femininity, and 20 are fillers (neutral). The BSRI Short Form consists of the first 30 items of the original BSRI and uses 10 items from each subscale. Each respondent receives a masculinity and femininity score. Sex-typed individuals are those who receive a score above the median on the sex-congruent scale and below the median on the sex-incongruent scale (e.g. feminine-typed females). Cross-sex-typed individuals are those have the opposite pattern (e. g. masculine-typed` females). Undifferentiated individuals are 
those who score below the median on both scales, and androgynous individuals are those who score above the median on both scales.

The construction of the BSRI was based on two specific theoretical assumptions (Bem, 1984); First, largely as a result of historical accident, the culture has clustered a heterogeneous collection of personality attributes into two mutually exclusive categories, each category considered by the culture more characteristic of and more desirable for one or the other of the two sexes. These cultural expectations or stereotypes are well known by virtually all members of the culture. Second, individuals differ from one another in the extent to which they utilize these cultural definitions of gender appropriateness as idealized standards of masculinity and femininity against which to evaluate their own personality and behavior. In particular, these definitions are very salient for sex-typed individuals, who are motivated to act consistently with them. According to Bem (1984), for androgynous individuals, cultural definitions of femininity and masculinity are less salient, and therefore androgynous individuals are less likely to regulate their behavior according to definitions of male and femaleness.

\section{Psychological Gender \& Leadership Effectiveness}

Although research has consistently found that effective leadership is perceived by most of society as characterized by traits associated with the masculine sex-type, extensive leadership literature indicates that the most effective leadership requires "consideration," or employee-oriented behaviors and "structuring" or directive, production-oriented behaviors 
(Cann \& Siegfried, 1990). Effective leadership is generally defined as the ability to recognize, respond and adapt to a variety of different task and relationship situations in a constructive way. In order to be able to respond to differing situations, a leader must have differing skills. Consideration and structuring leadership styles reflect these different skills. Cann and Siegfried (1990) hypothesized that these dimensions are parallel to stereotyped masculine or agentic behaviors and feminine or communal behaviors. They conducted two studies to provide an empirical comparison of the masculinity-femininity of the leadership styles of consideration and structuring.

The results showed significant positive correlations between masculine sex-type and structuring leader behaviors; and feminine sex type and consideration leader behaviors. This suggests that an androgynous leader, one whose psychological gender is high on both masculine and feminine sex-type behaviors, would be especially effective because of the ability to draw on both necessary leadership styles; consideration and structuring. This study suffers from two sample limitations. First, the numbers of the samples were very small, potentially limiting statistical power. Second, the sample was drawn from a well defined population, that is undergraduates in psychology courses. The authors contend there is no significant impact on the research from this selection procedure, citing other researchers' results that have found no significant differences between the study population and practicing managers. This researcher believes these limitations do not weaken the results. Moreover, since the aim was to correlate perception of various 
relevant constructs, this study does not examine correlations with actual leader behaviors; a relationship to be examined in subsequent research.

Hackman, Hills, Furniss and Paterson (1992) investigated the relationship between perceived gender-role characteristics and "transformational and transactional leadership." Transformationa? leadership is high on both task-oriented behaviors and relationship -oriented behaviors, whereas transactional leadership is a more traditional leadership style. The authors describe transformational leadership as characterized by "charisma, inspirational leadership, intellectual stimulation, individualized consideration, and extra effort," (Hackman et. al, (1992), p. 312). The authors described transactional leadership as characterized by "contingent reward, and management by exception" (Hackman et. al., (1992), p. 312). Like the structuring and consideration leadership styles, both transformational and transactional leadership styles are considered necessary for effective, adaptable leadership. Thus, the researchers examined the correlation between these necessary leadership styles and masculine, feminine and androgynous behaviors.

Analysis revealed there was a positive relationship between both feminine and masculine factors and transformational leadership, with a somewhat stronger positive relationship existing between femininity and transformational leadership. Furthermore, a significant positive correlation was found between perceived gender characteristics and transformational and transactional behaviors. Transformational leadership is seen by the authors as the foremost effective leadership 
style, which encompasses both high task orientation and high relationship orientation. The authors suggest that, based on this research, transformational leadership requires a gender balance that must encompass strong, positive feminine and masculine characteristics.

Bushardt, Fowler and Caveny (1987) conducted an investigation into sex-role behavior and leadership among nurses in a hospital. The authors chose this group because females are the norm in this profession, resulting in the reduction in stereotypical bias. They gave the BSRI and the Hersey Blanchard leadership questionnaire to 92 female registered nurses who occupied supervisory positions of leadership. The Hersey Blanchard measures four leadership styles, SI- high task and low relationship behaviors, SII - high task and high relationship behaviors, SIII - low task and high relationship behaviors and SIV - low task and low relationship behaviors. The authors were particularly interested in the subordinate's view of the supervisor's leader and gender behavior, thus, they asked the nursing supervisors to give an "other leadership" form and a modified BSRI to a subordinate that the nurse felt could describe her well.

The results indicated that the clear majority of the supervisors (70\%) were perceived as using Leadership Style 2, high task and high relationship behaviors. No significant relationship was found between sex -role behavior and leadership style. The results, however, revealed generally low scores on leadership effectiveness. Relative to androgynous, masculine, or feminine-typed behaviors, the least effective group were the undifferentiated leaders. Thus, the authors conclude that 
those leaders who display sex-role behavior, regardless of whether they are androgynous, masculine or feminine, are likely to be judged as more effective leaders by their followers.

Goktepe and Schneier (1988) conducted a study to examine the effects of gender and sex in evaluating emergent leaders in small groups. Data were collected on two occasions from 122 subjects in mixed sex groups performing "sex-neutral " tasks for valued rewards over many weeks of interaction. This study asked the following questions, 1) Will the leader's sex influence ratings of the leader's effectiveness evaluations in small task groups? and 2) Will leaders with androgynous gender role characteristics receive higher effectiveness evaluations than leaders with masculine or feminine gender role characteristics? In order to answer these questions the subjects were given the BSRI to indicate gender role. Additionally, the group members individually voted in a secret ballot for their choice of leader. Finally, leader effectiveness was assessed by asking each member of each group to rate the leader's overall effectiveness as a leader or organizer of the group.

Results showed that there were neither significant differences between effectiveness evaluations received by male and female leaders, nor among ratings received by leaders with masculine, feminine, or androgynous gender role orientations. These results, however, must be tempered by some limitations of this study. First, at Time 1 , of the 28 leaders, there were 13 masculine, 6 feminine, 5 undifferentiated, and 4 androgynous leader types. At Time 2, there were 13 masculine, 5 feminine, 5 undifferentiated and 4 androgynous leader types. These low 
numbers severely weaken the power of the data analyses. A second weakness is this study's assessment of leadership effectiveness. As Eagly and Karau's (1990) study illustrated, group members often define leadership as solely task-oriented contributions, and disregard relationship oriented contributions. Since this study did not offer a leadership definition, one is unclear about how the members are defining and evaluating leadership effectiveness. The members may be falling prey to societal stereotypes of leadership. Although this study found no relationship between leadership effectiveness and androgyny, study weaknesses may limit the strength of conclusion.

Baril, Elbert, Mahar-Potter and Reavy (1989) conducted a survey to answer the question: Are androgynous managers really more effective? The authors hypothesized that the androgynous supervisor should be most successful both in terms of superior ratings and subordinate satisfaction. In addition, they hypothesized that female supervisors high on masculinity should be more successful than female supervisors low on masculinity. The authors used Spence's Personal Attributes Questionnaire (PAQ) and the BSRI to measure the sex-role orientation of 65 first line supervisors from seven organizations. They also had these supervisors complete leader behavior scales including the Leadership Behavior Description Questionnaire (LBDQ). A total of 561 of the supervisors' subordinates completed the Job Descriptive Index to assess satisfaction with the supervisor as well as describing their supervisor with the LBDQ. Finally, two of the supervisors' superiors 
rank ordered and rated the supervisors on perceived overall effectiveness.

The authors used a regression analysis to determine how the successful androgynous supervisors differed from those who were rated less successful. However, the labels and categories used in the regression model are confusing including; bad, unhappy, tough, outgoing, perfect, pleasant, and mild. The origins of these terms are unclear, as well as the relevance to the measured leadership outcomes.

The results of this study revealed that those who scored high on masculinity and femininity (androgynous) and low on both (undifferentiated) were rated by their superiors as least effective. The most effective supervisors were high on either masculinity or femininity but not both. However, consistent with previous research, successful female supervisors were found to be higher on masculinity than were unsuccessful female supervisors and more feminine than male supervisors.

Although, once again, this study directly addresses the issue of androgyny and leadership effectiveness, there are, once again, limitations to this study. First, as mentioned above, the terms used in the regression analysis are confusing and seem irrelevant. It is difficult to determine exactly how the authors came up with these terms and therefore how they conducted their statistical analysis. Second, among the 65 first line supervisors, only 12 were female. This calls into question both the validity of a comparison among such different sample numbers, as well as the external generalizability. Third, in a study comparing 
leaders of different gender orientation, this study fails to make any mention of how many subjects were androgynous, feminine, masculine or undifferentiated. Thus, it is impossible to tell whether they had a sufficiently large sample of androgynous leaders. Finally, the authors note that they drew their sample from small organizations in a non metropolitan area where traditional values and attitudes may be emphasized. In this environment, both responses to androgyny and the actual form it takes are likely to be different from other situations.

Limitations in mind, Baril et. al. (1989) offer some interesting conclusions. First, the authors contend that androgynous managers are most effective in certain situations - a contingency approach. Also, they point out that there is a growing body of commentary that suggests that androgyny can have substantial negative consequences (Kelly \& Worell, 1977). These consequences might be due to anxiety-producing conflict between assertive tendencies and empathy and warmth. Another negative consequence might be depression caused by social pressure placed on androgynous individuals to conform to sex-role stereotypes. The authors, therefore, believe that the relationship between sex-role orientation and leadership effectiveness will vary as a function of situational factors and the way in which different styles are integrated and displayed. Therefore, specific contextual factors must always be considered in estimating how and to what extent sex-role orientation relates to managerial performance. 
Psychological Gender, Self-Monitoring \& Leadership

\section{Psychological Gender \& Leadership Emergence}

Gurman and Long (1992) investigated the relationship between gender orientation and emergent leader behavior in a study of mixedsex and single-sex groups. Emergent leaders are those people who become leaders, as opposed to appointed or structural leaders. The authors felt they must control for the sexism that works against women in mixed sex groups, so they concentrated mainly on all-women groups. The study examined the relationship between masculine and feminine scores and leadership effectiveness as determined by peer ratings and self ratings in all female groups.

Their results showed no relationship between peer ratings of task and relationship leadership and gender orientation. However, femininity was correlated with both measures of self-rated leadership and masculinity was correlated with the self-rated task leadership. Since these findings seem contrary to much of the current literature, the authors suggest further research to clarify these discrepancies. The limitations of this study may be overcome with a longitudinal replication study using real project groups for a longer period of time. The longitudinal replication would decrease the impact of sexist stereotypes (Eagly \& Karau, 1991), thus allowing the use of mixed-sex groups which would increase external validity.

\section{SELF-MONITORING AND LEADERSHIP}

The construct of self-monitoring has been identified by researchers as having the potential to be a crucial predictor of the 
variance in leadership. Self-monitoring refers to differences between individuals' expressive self-presentations in varying environments. The self-monitoring scale divides people into two groups, high self-monitors and low self-monitors (Snyder, 1987; Fiske \& Taylor, 1991). High selfmonitors adapt their behavior to group norms, roles and other features of the social situation (Anderson, 1990). The behavior of low self-monitors is guided primarily by internal, dispositional features such as attitudes, values, and other personality traits. Hence, the behavior of low selfmonitors can be predicted accurately from attitudes (Ajzen, Timko, \& White, 1982). This is opposite for high self-monitors, who, since their behavior is guided by situations, are very sensitive to and accurate in diagnosing social cues in each situation (Anderson, 1990). Since high self-monitors display a variety of behaviors as they move from one situation to another, there is a low correlation between their behavior and their attitudes.

The social behaviors of both the high self-monitors and the low self-monitors are guided by their respective self-concept or self schema. For a high self-monitor, the self schema is described as pragmatic (Snyder, 1987), because it contains a variety of activities and roles that can be displayed or withheld as the situation dictates. In contrast, a low self-monitor has a principled self schema (Snyder, 1987), which is expressed through a unified set of values and attitudes that are displayed consistently from situation to situation. Thus, a high self-monitor surveys his or her environment and responds and adapts to it. A low self-monitor 
will be less responsive to the environment, being more consistent in different situations.

The most appropriate explanation of leadership emergence involves an interaction between the characteristics of the person and the demands of the environment: "Who becomes the leader of a given group engaging in a particular activity and what the leadership characteristics are in a given case are a function of the specific situation" (Jenkins, 1947, p. 75). Thus, a leader must survey the environment, identify problems and needs and respond to them. Self-monitoring has been embraced in the leadership field as a construct capable of measuring this responsiveness and flexibility. As illustrated by the following literature review, most of the research has been focused on self-monitoring and leadership emergence, suggesting that the person most able to respond to the needs of the group, presumably a high self-monitor, will emerge as leader. Some of the literature has focused on self- monitoring and leadership style or effectiveness. None of the literature, however, has examined the potential interaction of self-monitoring and androgyny and its effect on leadership emergence and effectiveness.

\section{Self-Monitoring and Leadership Emergence}

Anderson (1990) offers a brief history of the early research in this area, illustrating mixed results. The first study, conducted by Garland and Beard (1979), examined the relationship between self-monitoring and leadership emergence in a laboratory setting. They proposed that the effects of self-monitoring would depend upon the nature of the task 
confronting a group: When the task emphasized discussion and task competence was difficult to assess, a high self-monitor would be most likely to emerge as a leader. These conditions provide the opportunity to clarify the expectations of the group and to modify one's self-presentation according to these expectations. When task competence was clear, however, task performance was expected to be the most important predictor of leadership emergence. Garland and Beard (1979) found this to be true only in all female groups. Consequently, they found high selfmonitoring was related only to women's emergence as leaders; however, Ellis (1988) reported that high self-monitoring predicted leader emergence only for men. Seites and Anderson (1981) found that high self-monitors were more likely to emerge in larger groups while low selfmonitors were more likely to emerge in smaller groups. Wentworth and Anderson (1984) found no relationship between self-monitoring and leader emergence for men or women in mixed-sex groups that worked on masculine, feminine or neutral tasks. Finally, Snyder (1987) cites several additional unpublished studies that support a relationship between self-monitoring and leader emergence.

Ellis, Adamson, Deszca and Cawsey (1988) examined the relationship between self-monitoring and leadership emergence in a long-term field study of natural groups. Ellis et. al. (1988) sought to extend Garland and Beard's (1979) study described above by using a field study of natural groups instead of artificial groups in a laboratory. In particular, this study examined groups engaged in highly involving tasks over a substantial period of time. It was found that scores on both the 
longer and shorter versions of the Self-Monitoring Scale predicted perceptions of leadership. Participant's sex had no effect on the relationship between self-monitoring and leadership emergence. These findings seem to support the proposal that individuals who are cast into leadership roles are able to perceive the needs of their group and pattern their own behavior.

Kent and Moss (1990) conducted two studies to explore the perceptions involved with self-monitoring and leader emergence. The first study hypothesized that high self-monitors, being acutely aware of their social situations and possessing the ability to manipulate their behaviors to match the situation, are more likely to be aware of the behaviors necessary to emerge as leaders in the particular situations in which they find themselves. Thus, high self-monitors will be more likely to perceive that they possess the behavioral repertoire necessary to become leaders. The researchers surveyed 120 business students and found that high self-monitors do indeed perceive themselves as emergent leaders in typical group situations.

Kent \& Moss's (1990) second study extended the investigation by evaluating the perceptions of all group members concerning who emerged as the leader in group activities. Data were collected from 116 subjects who were members of a work group for the length of a semester. The results indicate that the high self-monitor is perceived not as assuming a leadership role, per se, but rather as having a more general influence over the group. While the high self-monitor sees herself or 
himself as a leader, others may see the high self-monitor as a valuable contributor to group processes.

Dobbins, Long, Dedrick and Clemons (1990) conducted two studies, a laboratory study and a field study, in order to investigate the influence of self-monitoring ability and biological sex on leader emergence. In the first study, groups composed of a male high selfmonitor, male low self-monitor, female high self-monitor, and female low self-monitor worked on a salary allocation task. At the end of the task, subjects completed questionnaires that asked them to select one group member as their leader and assessed the amount of influence each group member exerted during the discussion. As predicted, high selfmonitors emerged as leaders, exerted more influence on group decision, and initiated more structure than did low self-monitors. The hierarchical regression analysis suggested, however, that high self-monitors are more likely to emerge as leaders because they are perceived as initiating more structure than are low self-monitors. These findings imply that selfmonitoring affects emergence indirectly through leader behavior. Also as predicted, men were more likely to emerge as leaders than were women. The hierarchical regression analyses indicated that women were less likely to emerge as leaders largely because they were not perceived as initiating as much structure as were men. The second study found a positive correlation between self-monitoring and leader emergence for the members of nine all-male social organizations.

Ellis and Cronshaw (1992) attempted to further the understanding of the relationship between self-monitoring and leadership in groups by 
focusing on two moderators: sex of the group members and nature of the task confronting the group. The authors hypothesized that high selfmonitors would be related to leader emergence for males, but not for females, in mixed-sex groups. Further, the relationship between selfmonitoring and leader emergence was hypothesized to be stronger for a task providing minimal feedback on the task competence of group members. These hypotheses were tested in a long-term study of natural mixed-sex groups.

The findings of the study offered support for the sex-moderator hypothesis, but not the task-moderator hypothesis. Total self-monitoring scores were predictive of leader emergence for only the male subjects in mixed-sex groups. The authors suggest that when norms in mixed-sex groups discourage females from exerting leadership, self-monitoring theory predicts that high self-monitoring females would be most affected by this social information (Ellis \& Cronshaw, 1992). Furthermore, post hoc analyses suggested that high self-monitors emerge as group leaders because they are more adaptive in their behavior than low self-monitors. The authors suggest that high self-monitors may possess a type of "social intelligence," a trait, that allows them to monitor situations and modify their leader behavior as required in specific situations (Ellis \& Cronshaw, 1992). This social intelligence, combined with an "instrumental intelligence," which allows them to master the technical aspects of group tasks, may typify those individuals who consistently become leaders when sex-role norms and task characteristics are favorable to leader emergence. 


\section{Self-Monitoring and Leadership Effectiveness}

Few studies exist which test the relationship between selfmonitoring and leadership behavior or effectiveness. Anderson and McLenigan (1987) conducted a laboratory study and a field study to investigate the sex differences in the relationship between selfmonitoring and leader behavior. The literature indicates that there are no significant differences in group productivity or group satisfaction as a function of the sex of the group leader, however, it appears that group members "expect" the group leader to be a man although women and men will be equally effective if they are given a chance to occupy the leadership positions (Anderson \& Blanchard, 1982). Thus, the guiding assumption underlying Anderson and McLenigan's research is that women who are given leadership roles within a small group must engage in more impression-management behavior than men to establish credibility and legitimacy as role occupants. It was predicted that selfmonitoring ability would show a stronger relationship with leadership effectiveness for women than for men. In addition, self-monitoring would show a stronger relationship with task-oriented group behavior among female leaders than among male leaders.

When the leadership behavior of high and low self-monitoring men and women were analyzed, the data indicated that self-monitoring scores were significantly correlated with task-oriented behaviors for female leaders but not for male leaders (Anderson \& McLenigan, 1987). Self-monitoring scores were uncorrelated with social-emotional, 
considerate behavior for both female and male leaders. Hence, it appeared that high self-monitoring women were displaying a stereotypic "cross-sex" style of leadership that was bolstering their organizational effectiveness.

Other studies have found that self-monitoring can enhance the job performance of women in traditionally male occupations (e.g., computer sales, management). Anderson (1987) investigated the relationship of high self-monitors and performance in nontraditional occupations, by looking for an enhancement effect among men in the traditional female job of nursing. Self-monitoring was highly correlated to male nurses' job success but was uncorrelated with female staff nurses' job success. Selfmonitoring was also correlated with the job success of female nursing administrators, a job that is "nontraditional" for women in the sense it has masculine occupation expectations. The authors concluded that selfmonitoring ability can facilitate adaptation to non-traditional occupations for both men and women probably because the social skill associated with high self-monitoring can enhance perceptions of occupation legitimacy.

Finally, Zaccaro, Foti and Kenny (1991) investigated the relationship between perceived leader status across different group situations and individual sensitivity to social demands. Would high selfmonitors emerge as leaders across different types of group tasks and would these high self-monitors be more effective leaders? The researchers set up a laboratory study involving groups of all females and all males. Subjects rotated among four tasks with different leadership 
requirements. No subject was with the same group members twice. After each task, the subjects were asked to rate all group members on leader behavior and elect a leader for a "future" group. A critical question for this study was whether self-monitoring reflects a greater sensitivity to changing task requirements. The results tentatively support their hypotheses, in that individuals ranked as leaders were more likely than non-leaders to display relevant or required behaviors for two of the four group tasks. Self-monitoring was significantly correlated both with average leader rankings and with task-relevant behaviors on two of the tasks.

\section{SUMMARY OF PRIOR RESEARCH}

Although the literature review shows mixed results in both leadership's relation to psychological gender and self-monitoring, one can draw a few conclusions and make several suggestions for further research. The research shows that an effective leader is one who can respond to both task-oriented and relationship oriented situations. Furthermore, a person will emerge as leader, if she or he is able to identify and serve the needs of the group. The psychological gender literature leads to the assumption that the most effective leaders would be androgynous, that is those individuals who have a repertoire of behaviors including masculine or task-oriented, and feminine or consideration-oriented. Similarly, the androgynous individual should be the one most capable of serving the needs of the group, and therefore emerge as leader. The self-monitoring literature indicates that high self- 
monitors would emerge as leaders, because they are more able to isolate and respond to group requirements. Likewise, a high self-monitor should be the most effective leader, because this individual is the most responsive and flexible.

An area that has not been investigated, at all, is the potential interaction between psychological gender and self-monitoring on leadership effectiveness and emergence. It is the purpose of this research to investigate this relationship. An androgynous individual who is low self-monitoring might be unable to identify a task versus relationship need. Similarly, a masculine high self-monitor might recognize a need for consideration, but feel unable to meet this group requirement. Thus, this paper will explore whether an androgynous individual who is a high self-monitor might combine the sensitivity and flexibility of high self-monitoring with the behavioral range of androgyny to emerge as the most effective leader.

The mixed results found in the preceding literature were often due, in part, to limitations of that particular study. Specifically, researchers often used very small numbers of women or androgynous individuals, the tasks were often simple in complexity, low in discussion and short in duration, and leadership was left undefined, allowing subjects to use stereotypical visions of leadership. Some of these studies used mixedsex groups and some used single-sex groups. Using single-sex groups may diminish sex stereotype effects, however, mixed-sex groups are far more representative of the organizational world. (Although "glass ceilings" exist, limiting the amount of women in upper management, 
women are still a substantial presence in the organizational workforce.) If a researcher conducts a natural study in which the tasks included complex social interaction for an extended period of time, sex stereotypes should become irrelevant in leader behavior and emergence. This study will attempt to overcome the limitations of previous studies by correlating real leader behavior and emergence with psychological gender and self-monitoring in mixed-sex groups performing complex social and product oriented tasks over an extended time period.

\section{RESEARCH QUESTIONS}

Founded on the preceding literature review, this research attempts to establish answers to the following research questions: Does biological sex predict leader behavior? Does biological sex predict leader emergence? Does psychological gender predict leader behavior? Does psychological gender predict leader emergence? Does self-monitoring predict leader behavior? Does self-monitoring predict leader emergence? Does sex moderate the relationship between selfmonitoring and leader behavior or leader emergence? Does selfmonitoring moderate the relationship between psychological gender and leader behavior or leader emergence?

\section{RESEARCH HYPOTHESES}

Based on the preceding research questions, this study endeavors 
to test the following hypotheses:

$\mathrm{H} 1$ : No significant difference in leader emergence or leader behavior will be present between males and females.

H2: Androgynous individuals will emerge as leaders to a significantly greater extent than subjects of masculine, feminine or undifferentiated gender.

H3: Androgynous individuals will display significantly more leader behavior than individuals of masculine, feminine or undifferentiated gender.

H4: High self-monitors will emerge as leaders to a significantly greater extent than low self-monitors.

H5: Those individuals who are both high self-monitors and androgynous will emerge as leaders significantly more often than any other individual.

H6: Those individuals who are both high self-monitors and androgynous will display significantly more leader behavior than any other individual.

H7: Those groups with members who are both high self-monitors and androgynous will have significantly greater group performance than the all other groups.

\section{Subjects}

\section{METHODS}

The subjects were 64 students who participated in one of two sections of a graduate management course in an M.B.A. program. The class is an eight credit course, meeting for eight hours a week for ten 
weeks. Twenty-four females and 40 males were subjects. Work experience ranged from zero years of work to 32 years (mean $=6.922$, std. dev. $=6.729 ;$ median $=5$ ). When asked how many years of experience as a leader the subjects had, the numbers ranged from zero to 23 years $($ mean $=2.234$, std. dev. $=4.507$; median $=.5$ ). Most all of the subjects expect to complete their MBA and become managers or leaders in organizations in the U.S. or elsewhere. About half of these subjects currently work in organizations in varying levels of responsibility. Subjects were assigned to work groups and were required to complete numerous projects including one major marketing project that determined half of each subject's grade. Fifteen work groups were formed with a range of 3 to 5 members, with a mode of 4 . The tasks required of the group were discussion, problem-solving, market analysis, written reports and giving oral presentations.

\section{Measures}

Androgyny was measured at the beginning of the term using the Bem Sex-role Inventory Short Form (30 items). People are categorized as feminine sex-type, masculine sex-type, undifferentiated (low on both) and androgynous (high on both masculine and feminine) by this inventory. Test - retest reliability coefficients for both the original and short form range from .76 to .94 (Bieger, 1985). Internal consistency coefficients for both the original and short form range from .75 to .90 . Correlations between the original and short form range from +.85 to +.94 (Bieger, 1985). Goldsmith and Ekhardt (1984) factorially compared the 
original BSRI form with the short form, and the short form was found to be psychometrically superior.

Self- Monitoring was assessed using Snyder's (1986) 18 item Self-Monitoring scale. This scale has an internal consistency (coefficient alpha) of +.70 , higher than that of the original 25 - item measure (Snyder, 1986).

Leadership emergence was assessed using the General Leadership Impression (GLI) (Cronshaw \& Lord, 1987). This scale asks the subject about the leadership participation of another member in the group, as well as the willingness to elect this person leader in a future group. The GLI has been widely used for leadership emergence assessment and has an alpha coefficient of +.88. In addition to the GLI, each member was asked to rank each member as to the extent she or he acted as a leader. This provided a second measure of leader emergence.

The behavior of each individual as a leader was rated on the same survey using the Leader Behavior Questionnaire Form XII (LBDQ) and the Leadership Opinion Questionnaire (LOQ). The LBDQ is designed to obtain descriptions of an individual's leadership behavior from the people whom they supervise (Stogdill, 1963). Thus, this questionnaire was used to obtain a member's perception of the leader behavior of the other members of his or her group. The LBDQ has 12 subscales, four of which were used for this study. They are described as follows; 1) Initiating Structure - clearly defines her or his own role, and lets followers know what is expected of them; 2) Production Emphasis- 
applies pressure for output; 3) Consideration- has regard for the comfort, well-being, and contribution of his or her followers; and 4) Tolerance of Freedom- allows followers scope for initiative, decision and actions. The internal reliability for the LBDQ Form XII ranges from .70 to .87 on these subscales.

The LOQ is a measure of leaders' opinions about desirable leadership behavior (Fleishman, 1953a, 1957a). It is a vehicle for asking the respondent how she or he should behave as a supervisor, and is focused on the constructs of Consideration and Initiating Structure. Thus, the LOQ was used to assess each member's perception of his or her own leadership effectiveness. The LOQ has 40 items, equally divided between the subscales of Consideration and Initiating Structure. Internal reliability correlations for the $L O Q$ range from .70 to .89 .

Thus, each subject's leadership behaviors were rated by each other member of her or his team using the LBDQ and by his or herself using the LOQ. This is in addition to the leadership ranking and ratings.

Finally, the group was assessed for effectiveness. First, the groups, as a whole, received a rating for a group presentation from each of the instructors teaching the course. Second, the same rating form was given to peer members outside the group to complete, providing a peer rating score. Third, the industry representative completed the same form, evaluating the oral marketing presentation, and gave each group a rating. Feedback from the industry representatives, peers and instructors indicates that these ratings may have been completed with differing motivations. The instructors feel their ratings were the most rigorous, 
Psychological Gender, Self-Monitoring \& Leadership

being academically critical of presentation performance. The peer and industry representatives may have seen the ratings as an opportunity for support and encouragement. Nevertheless, these scores were averaged to obtain three comparable scores; peer, instructor and industry representative.

In summary, psychological gender was assessed using the Bem Sex-Role Inventory. Self-monitoring was assessed using Snyder's (1986) 18 - item self-monitoring scale. Leadership emergence was measured through subjects' rankings of group members and the General Leadership Impression (GLI) scale. Subjects rated their own leader behavior using the Leader Opinion Questionnaire (LOQ) and were rated by others using the Leader Behavior Description Questionnaire XII (LBDQ). Finally, group performance was rated by out-group peers, course instructors and an industry representative.

\section{Procedure}

During the first week of the term, the subjects were given Questionnaire \#1 for completion. This questionnaire included the demographic information, Snyder's Self-Monitoring Scale and the Bem Sex-role Inventory. The formation of the teams was done in a stratified random method, randomly assigning equal numbers of men and women to the groups. In addition, groups were formed with so that half of the groups included androgynous high self-monitors and the other half included androgynous low self-monitors. The rest of the subjects were randomly distributed amongst the 15 groups. Please see Table 1 for a 
breakdown of expected numbers of individuals per cell, based on psychological gender type and self-monitoring type. Thus, 64 individuals became members of long-term project teams based on their selfmonitoring scores and gender orientation.

Insert Table 1 about here

In the last week of the term, (about 9 weeks later) after the groups had completed the majority of the group's term project, the subjects completed Questionnaire \#2. Questionnaire \#2 included rankings of each member on leader emergence; the Leader Opinion Questionnaire, the Group Functioning measure, and the Leader Behavior Descriptive Questionnaire. At the same time, after the group had completed the oral marketing presentation, a group effectiveness and performance form was completed by 1) the out-group peer members, 2) the course instructors and 3 ) the industry representative who witnessed the presentation.

\section{RESULTS}

Although 100 students were expected to enroll in the targeted classes, an unusual phenomena occurred, and the course was one of a very few on campus which was under-enrolled. The result of this underenrollment was that the sample size went from the expected 100 subjects down to 64 subjects. All students in the course agreed to participate, 
however. Unfortunately, this smaller sample size negatively affected the power of all between subjects comparisons. After splitting groups twice, once for psychological gender and once for self-monitoring, cell sizes included approximately 16 subjects, with some as low as 9 and 10 subjects. These disappointing numbers adversely impacted the power of the analyses to detect differences between groups, as demonstrated in the following discussions. Please see Table 2.1, Table 2.2 and Table 2.3 for a correlation matrix of relevant variables.

Insert Tables 2.1, 2.2 and 2.3 about here

The correlations reveal some interesting information about the variables and measures. Androgyny is correlated most strongly with selfperceived consideration behavior $(r=.32, p<.001)$. Interestingly, androgyny has a slightly negative relationship to group performance ratings by instructors and peers $(r=-.22$ and -.21 ; respectively); however, no relationship exists with group performance ratings by industry representatives. Self-monitoring is not significantly related to any other variable. Both self-monitoring and androgyny are two-level categorical variables, which decreases their ability to have significant relationships with other variables.

Leader emergence rankings and ratings are significantly related 
$(r=-.82, p<.001)$. The relationship is negative because top leaders were given a rating of five and a ranking of one (i.e. scoring scales were reversed). Both ratings and rankings were significantly related to numerous leader behavior measures. In particular, peer ratings were very highly correlated with production emphasis and structuring leader behaviors ( $r=.73$ and .78 , respectively; $p<.001)$. These correlations indicate that the subjects considered task-oriented leader behavior to be most important in defining leadership, perhaps neglecting, to some degree, process activity.

The leader behavior ratings show some intercorrelations. Some of these subscales are more similar to others. For example, production emphasis and structuring are both task oriented activities and are highly correlated $(r=.86, p<.001)$. Of some concern is the lack of relationships between self and other-perceived consideration $(r=-.0059)$ and self and other-perceived structuring $(r=.1123)$. In terms of the group performance correlations, the industry representative rating is not correlated with any other variable. The instructor ratings are only correlated with peer ratings of group performance. Peer ratings were also correlated with the other-perceived leader behaviors, consideration $(r=.29, p<.05)$ and production emphasis $(r=.26, p<.05)$.

H1: No significant difference in leader emergence or leader behavior will be present between males and females. Since repeated measures were used to assess leader behavior and leader emergence (e.g. LOQ, LBDQ and leader rating) a MANOVA was used to assess the significance of all of leader behavior and leader emergence ratings. 
Since leader emergence rankings are non-parametric, the MannWhitney $U$ was used to test this variable for significance. MANOVA results support this hypothesis. No significant differences between females and males were found for leader emergence or leader behavior (F $(10,53)=1.22165, p=.299$; for Rank, the nonparametric, MannWhitney $U=441.5, p=.5929)$.

H2: Androgymous individuals will emerge as leaders to a significantly greater extent than subjects of masculine, feminine or undifferentiated gender. The results do not support this hypothesis. An ANOVA was used to test significant differences found in leader ratings and the Mann-Whitney was used to test the significance of the nonparametric, leader rankings. No significant differences were found between androgynous subjects and other subjects on leader emergence ratings $(F(10,53)=2.924, p=.092)$ or rankings (Mann-Whitney $U=$ $310.0, p=.0838$ ), although the effects were in the expected direction and approached significance (rating: androgynous, $M=3.439, \mathrm{SD}=.807$, vs. other, $M=3.066, S D=.807$; ranking: androgynous, $M=2.330, S D$ $=1.106$, vs. other, $M=2.80, S D=1.010$ [for rank $1=$ high, $5=$ low]).

H3: Androgymous individuals will display significantly more leader behavior than individuals of masculine, feminine or undifferentiated gender. Multiple dependent variables were combined to assess leader behavior, including four peer-rated subscales and two self-rated subscales, requiring the use of a MANOVA to assess the significance of differences in leader behavior among those subjects of different psychological gender. MANOVA results do not support this 
hypothesis. No significant differences were found between androgynous subjects and others on ratings of leader behavior $(F(10,53)=1.00871, p$ $=.449$ ). Please see Table 3 for leader behavior means for androgynous versus other individuals. An examination of the table indicates the means for the androgynous individuals are always higher. Consistently, androgynous individuals were rated as having more leader behavior.

Insert Table 3 about here

H4: High self-monitors will emerge as leaders to a significantly greater extent than low self-monitors. An ANOVA was conducted to test whether significant differences in leader emergence ratings exist between high and low self-monitors. Likewise, the Mann-Whitney was used to test the significance of differences in the nonparametric, leader emergence rankings. ANOVA results do not support this hypothesis, $F(10,53)=.23605, p=.629$. Likewise, the nonparametric test, MannWhitney, used for ranking, shows no support, $U=507.5, p=.9517$. No significant differences were found between high self-monitors and low self-monitors on ratings and rankings of leader emergence.

H5: Those individuals who are both high self-monitors and androgynous will emerge as leaders significantly more often than any other individual. An ANOVA was used to test whether significant differences in leader emergence ratings exist between two groups, 
androgynous, high self-monitors and other-gender, low self-monitors.

Because the dependent variable was a four level variable (androgynous, high self-monitors; androgynous, low self-monitors; other-gender, high self-monitors; and other-gender low self-monitors), the Kruskal-Wallis test was used to assess differences in the nonparametric, leader emergence rankings. Neither ANOVA results nor results from the Kruskal-Wallis nonparametric test for rankings support this hypothesis. No significant differences were found between androgynous high self-monitors and others in ratings and rankings of leader emergence $(F(8,53)=.0266, p$ $=.871 ; \mathrm{chi}^{2}=3.0176, \mathrm{p}=.3889$ ). However, the means are in the expected direction. Androgynous high self-monitors received higher ratings on leader emergence than androgynous low-self-monitors and othergender, low self-monitors and higher leader emergence rankings than all other groups. Please see Table 4 for a the means of each of these groups on leader emergence and leader behavior.

Insert Table 4 about here

H6: Those individuals who are both high self-monitors and androgymous will display significantly more leader behavior than any other individual. Leader behavior was measured using a total of 6 subscales, so a MANOVA was conducted in order to determine whether significant differences exist in leader behavior due to differences in self- 
monitoring and gender. MANOVA results do not support this hypothesis. No significant differences were found between androgynous high selfmonitors and others on leader behavior $(F(8,53)=.79314, p=.611)$. As in previous hypotheses, the means are consistently in the expected direction. Although not significant, in all but one area, androgynous high self-monitors were rated higher than any other group on leader behavior.

H7: Those groups with members who are both high self-monitors and androgynous will bave significantly greater group performance than the all other groups. Group performance was assessed by combining three measurements, industry representative ratings, class instructor ratings and peer ratings. Thus, a MANOVA was conducted in order to determine whether significant differences in group performance exist due to self-monitoring and gender. MANOVA results do not support this hypothesis. No significant differences between androgynous high self-monitors and others were found on the three measures of group performance $(F(3,31)=.48842, p=.693)$. Please see Table 5 for the means on group performance by gender and self-monitoring. 


\section{EXPLORATORY ANALYSIS}

Based on the limitations described above by small sample size, this researcher statistically doubled the sample's data in order to conduct some exploratory analysis. This was accomplished by having the computer duplicate the information for each case, then combining the two identical samples of 64 to form one 'doubled' exploratory sample of 128 . Recognizing the variance would be artificially restricted by simply doubling the current sample, this procedure still offers some insight into what the results might be if the sample size were larger.

Many of the exploratory analyses results are encouraging, however, some are not. With the number of cases doubled, Hypothesis 1 is not supported. Biological sex did appear to have a significant multivariate effect on leader behavior and leader emergence $(F(7,120)$ $=3.19858, p=.004)$.

Hypothesis 2 was supported with an increased sample size. Androgynous individuals emerged as leader to a significantly greater extent than subjects of all other genders $(F(1,126)=5.94290, p=.016$; Mann-Wallis $U=1240.0, p=.0141)$. Likewise, Hypothesis 3 was supported by the multivariate analysis, indicating that androgynous individuals displayed significantly more leader behavior than other subjects $(F(9,118)=2.39087, p=.016)$. Hypothesis 4 was not supported, high self-monitors did not emerge as leaders significantly more than low self-monitors.

Within the exploratory analysis, Hypothesis 5 was partially supported. Those individuals who are both high self-monitors and 
androgynous scored significantly higher than others on leader emergence ratings $(F(2,124)=3.127, p=.047)$ but not on leader emergence rankings (Chi² pearson $=.143459, p=.705)$.

Hypothesis 6 was not supported by the exploratory analysis. The multivariate analysis revealed that individuals who are both high selfmonitors and androgynous did not display significantly more leadership behavior.

Most interesting, however, are the exploratory results for the last hypothesis. This hypothesis examines group performance. Since almost half of the data for Hypothesis 7 was lost to missing values, doubling the sample size restored the sample size to a little above what it should have been originally (original number of cases $=64$, number of cases for $\mathrm{H} 7=$ 37, exploratory case number for $\mathrm{H} 7=74$ ). Hypothesis 7 was supported by the results of the exploratory multivariate analysis $(F(3,68)=2.74055$, $p=.050)$. Those groups with androgynous high self-monitors were rated significantly higher in group performance by industry representatives, class instructors and out-group peers than any other group.

\section{DISCUSSION}

Many people view leadership as primarily concerned with taskoriented behavior. Those individuals who get the job done are seen as effective leaders. Organizational research, however, has indicated that effective leaders are those who display both relationship-oriented and task-oriented behaviors. To be truly effective in a long-term group setting, a leader needs to successfully facilitate the accomplishment of 
tasks as well as facilitate the group process. Not surprisingly, relationship-oriented activity, or consideration, has been correlated with feminine characteristics, while task-oriented activity or structuring, has been correlated with masculine characteristics. This would indicate that, contrary to popular belief, the most effective leader would be one who displays both feminine and masculine sex-typed characteristics; an androgynous person. Furthermore, a leader is successful when she or he is able to adapt to alternative situations. Theoretically, a person who is a high self-monitor, one who constantly perceives and adapts to situational variables, would be more successful as a leader than a low self-monitor, one who maintains consistent behaviors. Thus, research theory indicates that those who are androgynous, high self-monitors should emerge as leaders more often and display more leader behavior than others.

Although this study was designed to establish the empirical relationship between psychological gender, self-monitoring and leadership, the results from this study yield few new contributions to the field of psychology. Between groups of varying psychological gender and self-monitoring, significant differences in leader behavior and leader emergence were minimal.

Biological sex was expected to have no effect on leader emergence and leader behavior, and it did not. There were no significant differences between females and males on leader emergence ratings or rankings, or on self-perceived and other perceived leader behavior. 
Psychological gender, particularly androgyny, was expected to predict who would emerge as leaders and who would display the most leadership behavior. However, the results showed that there were no significant differences between androgynous individuals and others on leader emergence and all of the leader behavior except self-rated consideration. Androgynous individuals saw themselves as displaying more considerate behavior than others in the group. Furthermore, although the differences in leader emergence and behavior did not reach significance, they were consistently in the expected direction. Androgynous individuals displayed more leader behaviors than others and emerged as leaders slightly more often than other members in the group. For example, 32 percent of androgynous individuals were ranked as the top leader compared to 24 percent of the other participants.

Self-monitoring was expected to predict who would emerge as leader in a group. Contrary to this hypothesis, there were no significant differences between high self-monitors and low self-monitors on leader emergence rankings or ratings.

Psychological gender and self-monitoring were expected to interact with the result that those who are androgynous, high selfmonitors would display the most leader behavior and leader emergence. The results of this study showed no significant differences between androgynous, high self-monitors and others in leader emergence rankings and ratings or leader behaviors. Although not significant, once again, the differences that did exist were in the direction hypothesized. 
When subjects were asked to rank all members of the group to the degree an individual acted as a leader, individuals who were androgynous, high self-monitoring were ranked the highest. Likewise, leader emergence ratings for androgynous, high self-monitors were among the highest. In terms of leader behavior, androgynous, high selfmonitors were considered by both themselves and others to be most considerate, most tolerant of freedom, most structuring, most participative and least likely to be concerned about decision centralization.

An interaction between self-monitoring and gender was also expected to influence group performance. However, no significant differences in group performance ratings existed between the groups with androgynous, high self-monitors and other groups. The results of the test of this hypothesis must be tempered by two points. First, many of the industry representative ratings were unmarked, and therefore treated as a missing value. Some of the industry representatives failed to identify themselves on their rating forms, and, since all forms were the same, this data was indistinguishable from peer ratings. This resulted in the loss of substantial amounts of industry representative data. Thus, only 37 cases were available to test Hypothesis 7. This represents a little over half of the original small sample. The second point to consider is the effect of those remaining industry representative ratings. Ideally these ratings simulate to the greatest extent what group performance evaluations would be like in the 'real world'. The industry representatives had no knowledge of individual effort or previous group effort. One would expect their ratings to represent the most externally 
valid indicators of group effectiveness. However, the validity of this assertion my be weakened by instructor beliefs that the industry representatives were giving encouraging support versus critical evaluation. Be that as it may, the industry representative ratings were in the expected direction. In general, androgynous high self-monitors' groups were given higher ratings from the industry representative.

Although the differences in dependent variable means are encouraging support for the theoretical relationships, they are statistically inadequate to empirically support the hypotheses. There are four possible explanations for this outcome. First, the sample size provided insufficient power to draw out real, statistically significant, relationships. Second, regardless of sample size, the relationships do not exist. Third, the groups may be an inappropriate sample to test these hypotheses. Fourth, a combination of the above three; some relationships do exist and were not exposed due to small sample size or intervening variables, while other relationships simply do not exist. Based on the sample size, the theoretical foundations for the hypotheses, the research results and the exploratory analyses, the reasonable conclusion seems to be the fourth and last explanation.

With a larger sample size would significant relationships emerge? Although not significant, the differences that were found were consistently in the expected direction, leading one to surmise that with greater statistical power, those differences would become statistically significant. In order to illuminate these possibilities, an exploratory analysis was conducted after statistically doubling the sample size. With 
each case given an 'identical twin' some of these differences did become significant, indicating that a larger sample size would have resulted in support for multiple hypotheses. Within the exploratory analyses, Hypotheses 2 and 3 were supported; androgynous individuals emerged as leaders significantly more often and displayed significantly more leader behavior. Hypothesis 4 was not supported; high self-monitors did not emerge as leaders any more than low self-monitors. Hypothesis 5 was partially supported, with androgynous, high self-monitors receiving significantly higher scores than others on leader emergence ratings but not rankings. Hypothesis 6 was not supported by the multivariate analysis; androgynous, high self-monitors did not, in general, display significantly more leader behavior. Finally, Hypotheses 7 was supported by the exploratory analysis. Those groups with androgynous, high selfmonitors had significantly higher scores on group performance ratings than any other group.

Those hypotheses that involved androgyny seem to be the most consistently supported, possibly indicating that psychological gender may have a more direct effect on leadership than self-monitoring. One of the most robust and consistent findings in the literature was that selfmonitoring predicts leader emergence. However, there was no association between these variables in this study. Upon examination, it seems that the kinds of work groups used in this study versus those in the previous research may differ enough to alter the relationship of selfmonitoring to outcome measures. In short-term groups, the ability to adapt to environments may lead to a much greater leadership value by 
the group, compared to a long-term group where the group has the opportunity to learn what members' real skills are. Flexibility would still be required of a leader of a long-term group, but measuring a person's self-monitoring may not the most accurate way of assessing this.

The exploratory analyses offer insight into what effect these variables, self-monitoring and gender, might have on the outcome measures if the sample size were larger. Psychological gender would seem to have a greater, more direct effect than self-monitoring. If this study were enlarged, the result might be that self-monitoring drops out as a significant predictor of leadership in long-term work groups. Previous researchers have found that when task competence is clear, this variable will supersede self-monitoring in predicting leader emergence. Thus, inadequate sample size does seem to be a reasonable explanation for the lack of significant relationships. However, intervening variables may negate or hide relationships even if the sample size were larger.

There are a multitude of other variables that may be intervening in or causing limitations to this research situation. For example, this sample consisted of work groups comprised of M.B.A. students. In many ways, all of these individuals are training to be leaders. So perhaps the groups were made up of too many leaders and not enough followers. In addition, the outcome measure intercorrelations indicate that the participants considered task-oriented leader behavior to be the most important in defining leadership, neglecting relationship-oriented activity. The focus on task-oriented behavior may be due to the characteristics of the task or the characteristics of the sample. The task may have created 
a great deal of time pressure forcing task-oriented activity to be preeminent, eclipsing the value of process activity.

Also, upon examination of the raw data, this researcher often noted that participants would consider a person an effective leader, but would not want them to be leader in the future, affecting leader emergence measures. Participants sometimes seemed to rank an individual as a top leader, and then give this person low leader ratings; indicating, perhaps that the person acted as a leader by accomplishing tasks, but was not liked by the group. Thus, the subjects may have elected as leaders those individuals who got things accomplished, yet these same individuals may have been incapable of managing the group's process.

Finally, power strategies may have influenced these factors. This may be a very interesting variable to examine in this context in the future. What kinds of power bases do individuals of differing gender use, and how does that affect their leader emergence and behavior (e.g., reward, coercive, referent)?

The previous discussion leads to several suggestions for further research. First, a sample size that was at least twice the size of the present study would enable a true examination of the validity of the hypothesized relationships. With a sample of roughly 128 cases, the power of this study would reach .64, allowing an effect size of about .10; the high end of effect size ranges in this research field. This researcher believes the characteristics of the sample, although not representative of the general population, yield an accurate representation of the 
organizational environment where many group and leader situations exist. Thus, it is this population that requires examination into those variables that affect leadership. Second, in addition to self-monitoring, other variables could be assessed to examine whether other influences are affecting the hypothesized relationships. An index of flexibility, as well as measurements of an individual's use of power bases would provide interesting information. Third, to some degree, it seemed as if the subjects were describing leadership in a limited, task-oriented view. This would reflect the larger opinion that leadership includes only structuring behaviors. Nevertheless, it does not give an accurate picture of how much the subjects engaged in both product and process activity. In general, it did not seem like better measures of the variables were needed; however, perhaps better and more complete instructions for assessing leadership, composed of both consideration and structuring, may be required.

The importance of this type of research continues to grow. The rapidly changing environment is causing organizations to become more and more concerned with process activity. Projects which dominate the organizational scene, such as Total Quality Management, learning organizations and self-managed teams, all require leadership with solid relationship-oriented skills to enact participative management. A new kind of leadership is required for the next century, and with it, a new perspective on how sex-roles, or psychological gender, affect our organizations. 
Psychological Gender, Self-Monitoring \& Leadership

\section{REFERENCES}

Ajzen, I., Timko, C., \& White, J. B. (1982) Self-monitoring and the attitude behavior relation. Journal of Personality and Social Psychology. 42. 426-435.

Anderson, L. R. (1987). Self-monitoring and performance in nontraditional occupations. Basic and Applied Social Psychology. 8(1\&2), 85-96.

Anderson, L. R. (1990). Toward a two-track model of leadership training: Suggestions from self-monitoring theory. Small Group Research, 21. (2) $147-167$.

Anderson, L. R. \& Blanchard, P. N. (1982). Sex differences in task and social-emotional behavior. Basic and Applied Social Psychology. 3. 109-139.

Anderson, L. R. \& McLenigan, M. (1987). Sex differences in the relationship between self-monitoring and leader behavior. Small Group Behavior, 18(2), 147-167.

Bales, R. F. (1953). The equilibrium problem in small groups. In T.

Parsons, R. F. Bales, \& E. A. Shils (Eds.) Working papers in the theory of action. New York: Free Press.

Baril, G., Elbert, N., Mahar-Potter, S., \& Reavy, G. (1989). Are androgynous managers really more effective? Group \& Organization Studies, 14(2), 234-249. 
Bem, S. L. (1981). Gender schema theory: A cognitive account of sex typing. Psychological Review, 88, 354-364.

Bem, S. L. (1984). Androgyny and gender schema theory: A conceptual and empirical integration. Nebraska Symposium on Motivation, 32. 179-226.

Bieger, G. (1985). Bem Sex-Role Inventory. In Keyser, D. J. \& Sweetland, R. C. (Eds.) Test Critiques, Vol. III. Kansas City, MI: Westport Publishing Inc.

Brenner, O. C., Tomkiewicz, J, \& Schein, V. E. (1989). The relationship between sex-role stereotypes and requisite management characteristics revisited. Academy of Management Journal. 32(3), 662-669.

Bushardt, S., Fowler, A., \& Caveny, R. (1987). Sex-role behavior and leadership: An empirical investigation. Leadership and Organization Development Journal. 8(5), 13-16.

Cammann, C., Fichman, M., Jenkins, D., \& Klesh, J. (1979). The Michigan Organizational Assessment Questionnaire. Unpublished Manuscript. University of Michigan, Ann Arbor, Michigan.

Cann, A., \& Siegfried, W. D., (1990). Gender stereotypes and dimensions of effective leader behavior. Sex Roles, 23(7.8), 413-419

Cronshaw, S. F. \& Lord, R. G. (1987). Effects of categorization, attribution, and encoding processes on leadership perceptions. Journal of Applied Psychology, 72, 97-106. 
Dobbins, G., Long, W., Dedrick, E., \& Clemons, T. (1990). The role of self-monitoring and gender on leader emergence: A laboratory and field study. Journal of Management, 16(3), 609-618.

Eagly, A. H. \& Johnson, B. T. (1990). Gender and leadership style: A meta-analysis. Psychological Bulletin, 108(2), 233-256.

Eagly, A. \& Karau, S. (1991). Gender and the emergence of leaders: A meta-analysis. Journal of Personality and Social Psychology. 60(5). 685-710.

Eagly, A. H. \& Wood, W., (1991). Explaining sex differences in social behavior: A meta-analytic perspective. Personality and Social Psychology Bulletin, 17(3), 306-315.

Ellis, R. J. (1988). Self-monitoring and leadership emergence in groups. Personality and Social Psychology Bulletin, 14(4), 681-693.

Ellis, R. J., Adamson, R., Deszca, G., \& Cawsey, T. (1988). Selfmonitoring and leadership emergence. Small Group Behavior, 19(3). 312-324.

Ellis, R. J. \& Cronshaw, S. F. (1992). Self-monitoring and leader emergence: A test of moderator effects. Small Group Research, 23(1). 113-129.

Fiske, S. \& Taylor, S. (1991). Social Cognition, 2nd. Ed. NY: McGrawHill, Inc.

Fleishman, E. A. (1953). The description of supervisory behavior. Journal of Applied Psychology, 37 1-6.

Fleishman, E. A. (1957). A leader behavior description for industry. In R. M. Stogdill and A. E. Coons (Eds.), Leader Behavior: Its Description 
and Measurement. Bureau of Business Research, Ohio State University, Columbus, Ohio.

Freedman, S. M. \& Phillips, J. S.(1988). The changing nature of research on women at work. Journal of Management. 14(2), 231-251.

Garland, J., \& Beard, J. F. (1979). Relationship between self-monitoring and leader emergence across two task situations. Journal of Applied Psychology, 64, 72-76.

Goktepe, J. \& Schneier, C. (1988). Sex and gender effects in evaluating emergent leaders in small groups. Sex Roles, 19, 29-35.

Goldsmith, W. M., \& Ekhardt, B. N. (1984). Personality factors of men and women pastoral candidates, Part 2: Sex-role preferences. Journal of Psychology and Theology, $3,211-221$.

Gurman, E. \& Long, K. (1992). Gender orientation and emergent leader behavior. Sex Roles, 27(7,8), 391-400.

Hackman, M. Z., Hills, M. J., Furniss, A. H., \& Paterson, T. J. (1992).

Perceptions of gender-role characteristics and transformational and transactional leadership behaviors. Perceptual and Motor Skills. 75 311-319.

Heilman, M. E., Block, C. J., Martell, R. F., \& Simon, M. C. (1989). Has anything changed? Current characterizations of men, women, and managers. Journal of Applied Psychology, 74(6), 935-942.

Jenkins, W. O. (1947). A review of leadership studies with particular reference to military problems. Psychological Bulletin, 44, 54-79. 
Psychological Gender, Self-Monitoring \& Leadership

Kelly, J. \& Worell, J. (1977). New formulations of sex-roles and androgyny: A critical view. Journal of Consulting and Clinical Psychology, 45, 1101-1031.

Kent, R. L. \& Moss, S. E. (1990). Self-monitoring as a predictor of leader emergence. Psychological Reports, 66, 875-881.

Powell, G. N. (1988). Women and men in management. Newbury Park, CA: Sage.

Powell, G. N. \& Butterfield, D. A. (1989). The "Good Manager" Did androgyny fare better in the 1980's? Group \& Organization Studies. 14(2), 216-233.

Schein, V. E. \& Mueller, R. ( 1992), Sex-role stereotyping and requisite management characteristics: A cross cultural look. Journal of Organizational Behavior. 13, 439-447.

Seashore, S. E., Lawler, E. E., Mirvis, P., \& Cammann, C. (Eds.) (1982).

Observing and Measuring Organizational Change: A Guide to Field Practice. New York: Wiley.

Seites, N., \& Anderson, L. R. (1981, May). Emergent leadership as a function of self-monitoring and group size. Paper presented at the meeting of the Midwestern Psychological Association, Detroit.

Signorella, M. L. (1987). Gender schemata: Individual differences and context effects. New Directions for Child Development. 38, 23-37.

Snyder, M. (1987). Public appearances, private realities: The psychology of self-monitoring. New York: W. H. Freeman. 
Snyder, M. \& Gangestad, S. (1986). On the nature of self-monitoring:

Matters of assessment, matters of validity. Journal of Personality and Social Psychology, 51(1), 125-139.

Stogdill, R. M. (1963). Manual for the Leader Behavior Description Questionnaire - Form XII: An Experimental Revision. Bureau of Business Research, Ohio State University, Columbus, Ohio.

Wentworth, D. K. \& Anderson, L. R. (1984). Emergent leadership as a function of sex and task type. Sex Roles, 11, 513-524.

Zaccaro, S., Foti, R., \& Kenny, D. (1991). Selt-monitoring and trait-based variance in leadership: An investigation of leader flexibility across multiple group situations. Journal of Applied Psychology, 76(2), 308315. 
Psychological Gender, Self-Monitoring \& Leadership

Table 1: Potential subject cells based on Pychological Gender and Self-Monitoring (Based on normal distribution)

\begin{tabular}{|c|c|c|c|}
\hline Androgynous: & 16 Subjects & Feminine: & 16 Subjects \\
\hline $\begin{array}{l}\text { Low S-M } \\
8 \text { Subjects }\end{array}$ & $\begin{array}{l}\text { High S-M } \\
8 \text { Subjects }\end{array}$ & $\begin{array}{l}\text { Low S-M } \\
8 \text { Subjects }\end{array}$ & $\begin{array}{l}\text { High S-M } \\
8 \text { Subjects }\end{array}$ \\
\hline Undifferentiated: & 16 Subiects & Masculine: & 16 Subjects \\
\hline $\begin{array}{l}\text { Low S-M } \\
8 \text { Subjects }\end{array}$ & $\begin{array}{l}\text { High S-M } \\
8 \text { Subjects }\end{array}$ & $\begin{array}{l}\text { Low S-M } \\
8 \text { Subjects }\end{array}$ & $\begin{array}{l}\text { High S-M } \\
8 \text { Subjects }\end{array}$ \\
\hline
\end{tabular}


Table 2.1: Means \& Correlation Matrix

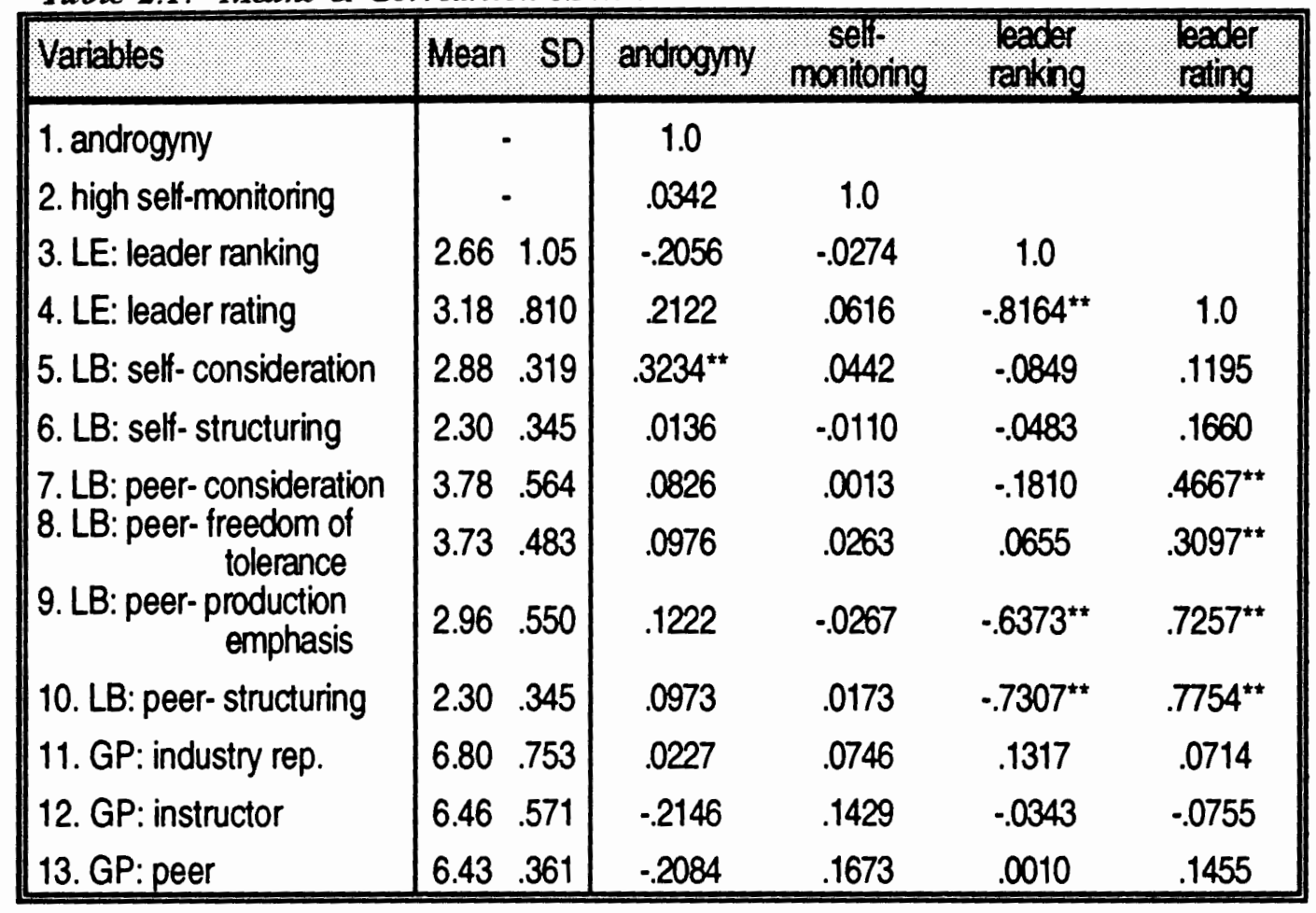

Note: $L E$ - Leader Emergence, LB - Leader Behavior, GP - Group Performance 'self -self rated, "peer' - peer rated; GP - 8 point scale, all others - 5 point scale; $L E$ ratings and rankings were reversed scored.

$N=64 ;{ }^{*} p=.05 \quad{ }^{* *} p=.01$ (two tailed) 
Psychological Gender, Self-Monitoring \& Leadership

Table 2.2: Correlation Matrix (continued)

\begin{tabular}{|c|c|c|c|c|}
\hline Variables & consideration & $\begin{array}{l}\text { self: } \\
\text { structuring }\end{array}$ & consideration & $\begin{array}{l}\text { Peet freedom } \\
\text { of toleranco }\end{array}$ \\
\hline 5. LB: self- consideration & 1.0 & & & \\
\hline 6. LB: self- structuring & .0234 & 1.0 & & \\
\hline 7. LB: peer-consideration & -.0059 & .2053 & 1.0 & \\
\hline $\begin{array}{c}\text { 8. LB: peer-freedom of } \\
\text { tolerance }\end{array}$ & .0413 & $.2523^{*}$ & $.6950^{*}$ & 1.0 \\
\hline $\begin{array}{l}\text { 9. LB: peer-production } \\
\text { emphasis }\end{array}$ & .1794 & .0818 & $.2891^{*}$ & .0025 \\
\hline 10. LB: peer- structuring & .0648 & .1123 & .1993 & .0052 \\
\hline 11. GP: industry rep. & .0896 & -.1127 & .0338 & .0403 \\
\hline 12. GP: instructor & .0845 & -2108 & -1272 & -.2303 \\
\hline 13. GP: peer & -.0437 & .0424 & $.2999^{*}$ & .0189 \\
\hline
\end{tabular}


Psychological Gender, Self-Monitoring \& Leadership

Table 2.3: Correlation Matrix (continued)

\begin{tabular}{|c|c|c|c|c|}
\hline Variables & $\begin{array}{l}\text { peerproduction } \\
\text { emphasis }\end{array}$ & $\begin{array}{l}\text { ofher:- } \\
\text { structuring }\end{array}$ & industry rep. & instructor \\
\hline $\begin{array}{l}\text { 9. LB: peer-production } \\
\text { emphasis }\end{array}$ & 1.0 & & & \\
\hline 10. LB: peer- structuring & $.8582^{* *}$ & 1.0 & & \\
\hline 11. GP: industry rep. & .2594 & .2162 & 1.0 & \\
\hline 12. GP: instructor & -.0238 & .0074 & -.1157 & 1.0 \\
\hline 13. GP: peer & $.2618^{*}$ & .2052 & .1066 & $.3550^{* *}$ \\
\hline
\end{tabular}


Psychological Gender, Self-Monitoring \& Leadership

Table 3: Comparison of means for leader behavior by androgynous versus other

\begin{tabular}{|c|cc|cc||}
\hline Leader Behavior & \multicolumn{2}{|c|}{ Androgynous } & \multicolumn{2}{|c|}{ Other } \\
\hline Peer Rating: & \multicolumn{2}{|c|}{ Mean } & SD & \multicolumn{2}{|c|}{ Mean } & $S D$ \\
\hline Consideration & 3.848 & .612 & 3.747 & .612 \\
Freedom of Tolerance & 3.803 & .319 & 3.701 & .538 \\
Production Emphasis & 3.059 & .319 & 2.913 & .574 \\
Structuring & 3.360 & .496 & 3.235 & .628 \\
\hline Self Rating: & Mean & $S D$ & Mean & $S$ \\
\hline Consideration & $3.037^{*}$ & .274 & 2.813 & .316 \\
Structuring & 2.310 & .394 & 2.300 & .327 \\
\hline
\end{tabular}

Note: peer rating measured with the $L B D Q$, self rating measured with the $L O Q$ $N=64 ;{ }^{*} p<.05$ 
Psychological Gender, Self-Monitoring \& Leadership

Table 4: Means of leader behavior and leader emergence by gender and self monitoring (Hypotheses 5\& 6: Table of Means)

\begin{tabular}{|c|c|c|c|c|c|c|c|c|}
\hline \multirow{2}{*}{$\begin{array}{l}\text { Dependent Variables } \\
\text { Leader Emergence }\end{array}$} & \multicolumn{2}{|c|}{$\begin{array}{l}\text { High SM } \\
\text { Androgynous }\end{array}$} & \multicolumn{2}{|c|}{$\begin{array}{l}\text { Low SM } \\
\text { Androgynous }\end{array}$} & \multicolumn{2}{|c|}{$\begin{array}{l}\text { High SM } \\
\text { Other }\end{array}$} & \multicolumn{2}{|c|}{$\begin{array}{l}\text { Low SM } \\
\text { Other. }\end{array}$} \\
\hline & Mean & $S D$ & Mean & $S D$ & Mean & $S D$ & Mean & $S D$ \\
\hline $\operatorname{Rar}$ & 313 & 1.25 & 2.348 & .998 & 2.777 & 1.00 & 2.822 & 1.03 \\
\hline Rating & 3.505 & .811 & 3.367 & .776 & 3.686 & .687 & 3.034 & .922 \\
\hline Leader $B$ & rean & $S D$ & Mean & $S D$ & Mean & $S D$ & Mean & $D$ \\
\hline \multicolumn{9}{|l|}{ Peer Rating: } \\
\hline Conside & 868 & .438 & 3.826 & .457 & 3.737 & .530 & 3.757 & 694 \\
\hline Freedom of Tolerance & 3.932 & .242 & 3.660 & .345 & 3.658 & .573 & 3. & .513 \\
\hline Production & 3.042 & .616 & 3.078 & .327 & 2.897 & .575 & 2.929 & .585 \\
\hline Structuring & 3.409 & .567 & 3.304 & .430 & 3.224 & .575 & 3.245 & .688 \\
\hline \multicolumn{9}{|l|}{ ielf Rating: } \\
\hline Consider & 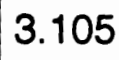 & 264 & 2. & .280 & 2.798 & .380 & 2. & .246 \\
\hline Structuring & 2.329 & .400 & 2.289 & .411 & 2.285 & .365 & 2.313 & .294 \\
\hline
\end{tabular}

Note: Leader emergence rank: $1=$ high $5=$ low, all others $1=$ low $5=$ high;

Leader Einergence rating measured with the GLI, peer rating measured with the $\angle B D Q$, self rating measured with the $L O Q ; N=64$ 
Psychological Gender, Self-Monitoring \& Leadership

Table 5: Means for group performance by gender and self-monitoring

\begin{tabular}{|c|c|c|c|c|c|c|c|c|}
\hline Group Perfomance & \multicolumn{2}{|c|}{$\begin{array}{l}\text { High SM } \\
\text { Androgynous }\end{array}$} & \multicolumn{2}{|c|}{$\begin{array}{l}\text { Low SH } \\
\text { Androgynous }\end{array}$} & \multicolumn{2}{|c|}{$\begin{array}{l}\text { High SN } \\
\text { Other }\end{array}$} & \multicolumn{2}{|c|}{$\begin{array}{l}\text { Low SM } \\
\text { Other }\end{array}$} \\
\hline Industry Rep. Rating & 6.804 & .753 & 6.594 & .795 & 6.694 & .758 & 6.85 & 7.95 \\
\hline Instructor Rating & 6.168 & .522 & 6.605 & .520 & 6.566 & .657 & 6.41 & .573 \\
\hline Peer Rating & 6.254 & .392 & 6.403 & .396 & 6.458 & .392 & 6.47 & .334 \\
\hline
\end{tabular}

Note: Ratings based on an 8 point scale;

Instructor \& Peer, $N=64 ;$ Industry Rep, $N=37$ 